\title{
Mechanical Thrombectomy for Acute Case Middle Cerebral Artery Occlusion Caused by Tumor Embolism: A Case Report
}

Takuya Moriyama, ${ }^{1}$ Yuri Sugiura, ${ }^{1}$ Yuto Hayashi, ${ }^{1}$ Fukuaki Kinoshita, ${ }^{1}$ Ryohei Yamamura, ${ }^{1}$ Masayuki Moriya, ${ }^{1}$ Chikao Tatsumi, ${ }^{1}$ Kazuyuki Nagatsuka, ${ }^{1}$ Masahiro Ishihara, ${ }^{2}$ Masami Nishio, ${ }^{2}$ Hiromi Tamura, ${ }^{3}$ Shiro Adachi, ${ }^{3}$ and Yuki Akazawa ${ }^{4}$

Objective: We report a case of acute middle cerebral artery (MCA) occlusion caused by tumor embolism.

Case Presentation: A 64-year-old man with lung cancer presented with sudden onset left-sided hemiparesis and sensory disturbance. Diffusion-weighted imaging (DWI) revealed hyper-intense foci in the right MCA territory and magnetic resonance angiography (MRA) demonstrated right MCA M2 segment occlusion. Mechanical thrombectomy (MT) was performed with Thrombolysis in Cerebral Infarction 2B recanalization. On histopathology, thrombus composed of fibrin and squamous cell carcinoma was observed. We diagnosed him with tumor embolism from lung cancer that invaded the pulmonary vein and the left atrium.

Conclusion: Tumor cells may be confirmed by pathological examination regardless of the morphology of the embolus. Pathological examination of the cerebral embolus is useful for the accurate diagnosis of ischemic stroke subtypes.

Keywords $>$ tumor embolism, stroke, thrombo-pathology, mechanical thrombectomy, lung cancer

\section{Introduction}

For acute ischemic stroke, mechanical thrombectomy (MT) is established as an effective treatment and is widely performed. The recanalization rate has been improved with the development of devices, and it has become possible to assess the cause of stroke by pathological examination of retrieved thrombi. In the case reported here, we diagnosed tumor embolism by pathological examination of the thrombus. As there are few reports of detection of tumor cells by

${ }^{1}$ Department of Neurology, Toyonaka Municipal Hospital, Toyonaka, Osaka, Japan

${ }^{2}$ Department of Neurosurgery, Toyonaka Municipal Hospital, Toyonaka, Osaka, Japan

${ }^{3}$ Department of Diagnostic Pathology, Toyonaka Municipal Hospital, Toyonaka, Osaka, Japan

${ }^{4}$ Department of Thoracic Oncology, Osaka Toneyama Medical Center, Toyonaka, Osaka, Japan

Received: February 3, 2020; Accepted: June 26, 2020 Corresponding author: Takuya Moriyama. Department of Neurology, Toyonaka Municipal Hospital, 4-14-1, Shibaharachou, Toyonaka, Osaka 560-8565, Japan

Email: jbtrbzzlislpi@yahoo.co.jp

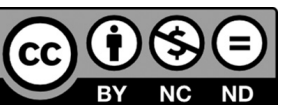

This work is licensed under a Creative Commons Attribution-NonCommercialNoDerivatives International License.

(C)2021 The Japanese Society for Neuroendovascular Therapy pathological examination, the case is reported with a review of the literature.

\section{Case Presentation}

The patient was a 64-year-old man who suddenly developed left-sided hemiparesis and sensory disturbance. He underwent brain magnetic resonance imaging (MRI) at another hospital and was diagnosed with acute cerebral infarction. The patient arrived at our hospital 208 minutes after onset. He was diagnosed with squamous cell carcinoma of the lung (cT4N3M0 Stage IIIB) 1 year previously and underwent chemoradiotherapy. He had a history of paroxysmal atrial fibrillation and lacunar infarction. He complained of strong malaise for 1 month and was hospitalized at another hospital. He had small-volume hemoptysis during hospitalization. On arrival at our hospital, he had left-sided facial palsy, hemiparesis and severe sensory disturbance, mild dysarthria, and left hemispatial neglect. National Institutes of Health Stroke Scale score was 10. MRI demonstrated hyper intensities from the right insular cortex to the right parietal lobe on diffusion-weighted imaging (DWI) (Fig. 1A). The DWI-Alberta Stroke Program Early CT Score was 8. On magnetic resonance angiography (MRA), the M2 segment of the right middle cerebral artery (MCA) was occluded (Fig. 1B). As intravenous thrombolysis with 


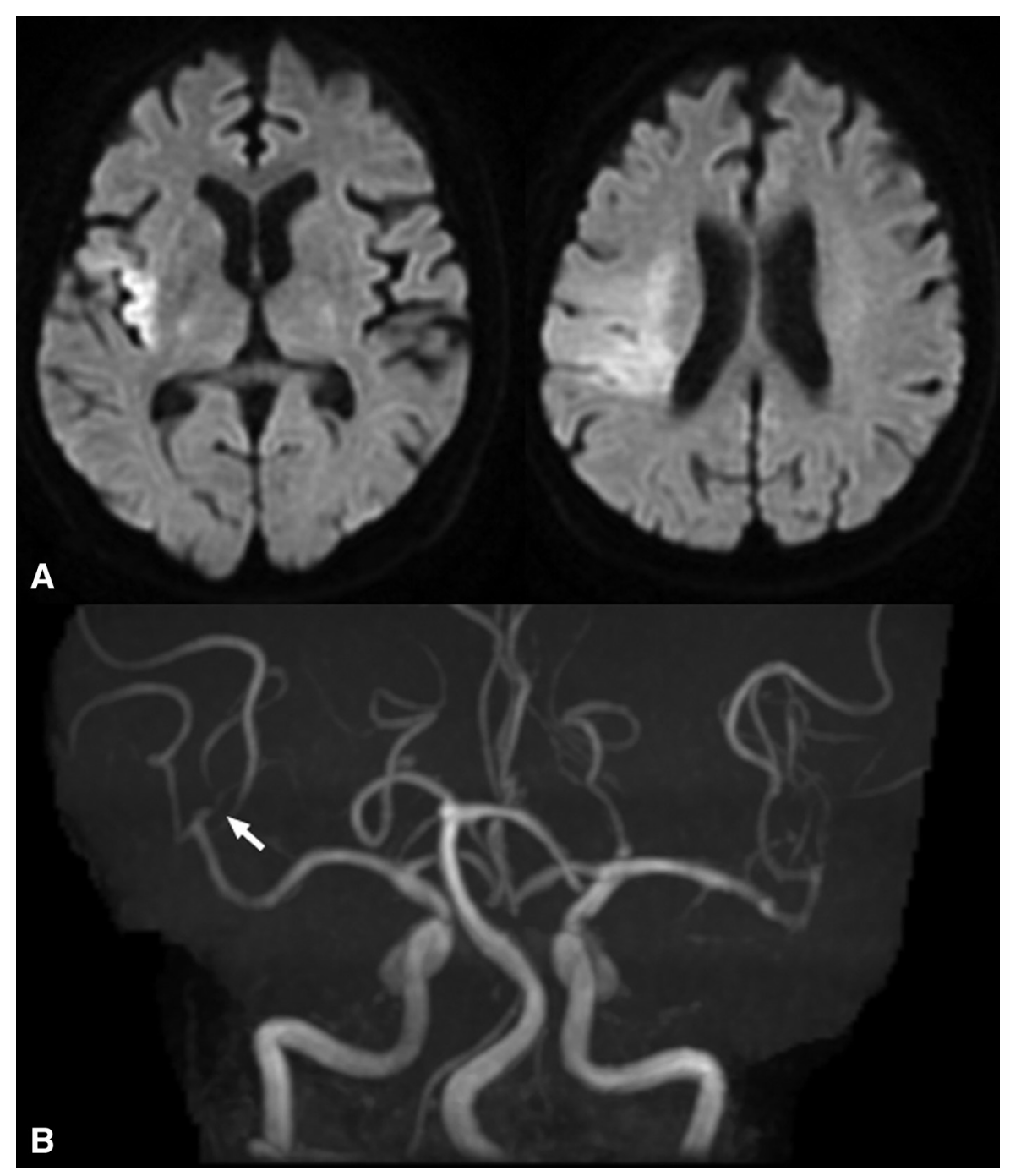

Fig. 1 (A) Axial diffusion-weighted images show acute ischemic lesion in the right MCA territory. (B) MRA shows right MCA M2 segment occlusion. (white arrow). MCA: middle cerebral artery; MRA: magnetic resonance angiography

recombinant tissue plasminogen activator (IV rt-PA) was contraindicated due to hemoptysis, MT was performed.

Endovascular treatment (Fig. 2): Treatment was initiated by groin puncture 241 minutes after onset and 33 minutes after arrival. A 9Fr Optimo (Tokai Medical Products, Aichi, Japan) was placed in the right internal carotid artery. Using a Penumbra ACE68 (Penumbra, Alameda, CA, USA), Trevo pro18 (Stryker, Kalamazoo, MI, USA), and CHIKAI 0.014-inch $200 \mathrm{~cm}$ (ASAHI INTECC, Aichi), the Trevo pro18 and CHIKAI were advanced across the lesion. The Penumbra ACE68 was placed in the proximal M1 segment of the right MCA. A Trevo $3 \times 20 \mathrm{~mm}$ (Stryker) was deployed across the occluded area. Immediate flow restoration was observed. The Optimo was inflated, and the Trevo was slowly removed with continuous manual aspiration through the Penumbra ACE68. A red thrombus of approximately $3 \mathrm{~mm}$ in diameter was retrieved. Thrombolysis in cerebral infarction 2B recanalization was achieved 40 minutes after puncture.

After the procedure, left-sided hemiparesis was rapidly improved. Left facial paresis, dysarthria, and left hemispatial neglect gradually disappeared, and ambulation became possible. Left-sided sensory disturbance remained. Pathological examination of the retrieved thrombus revealed squamous cell carcinoma cells along with fibrin (Fig. 3), and a diagnosis of stroke due to tumor embolism was made. On contrast-enhanced CT of the chest, a mass in the left hilar region infiltrating the pulmonary vein and left atrium was found (Fig. 4). Part of the invaded tumor and thrombus attached around it were considered to have caused embolism. As the 


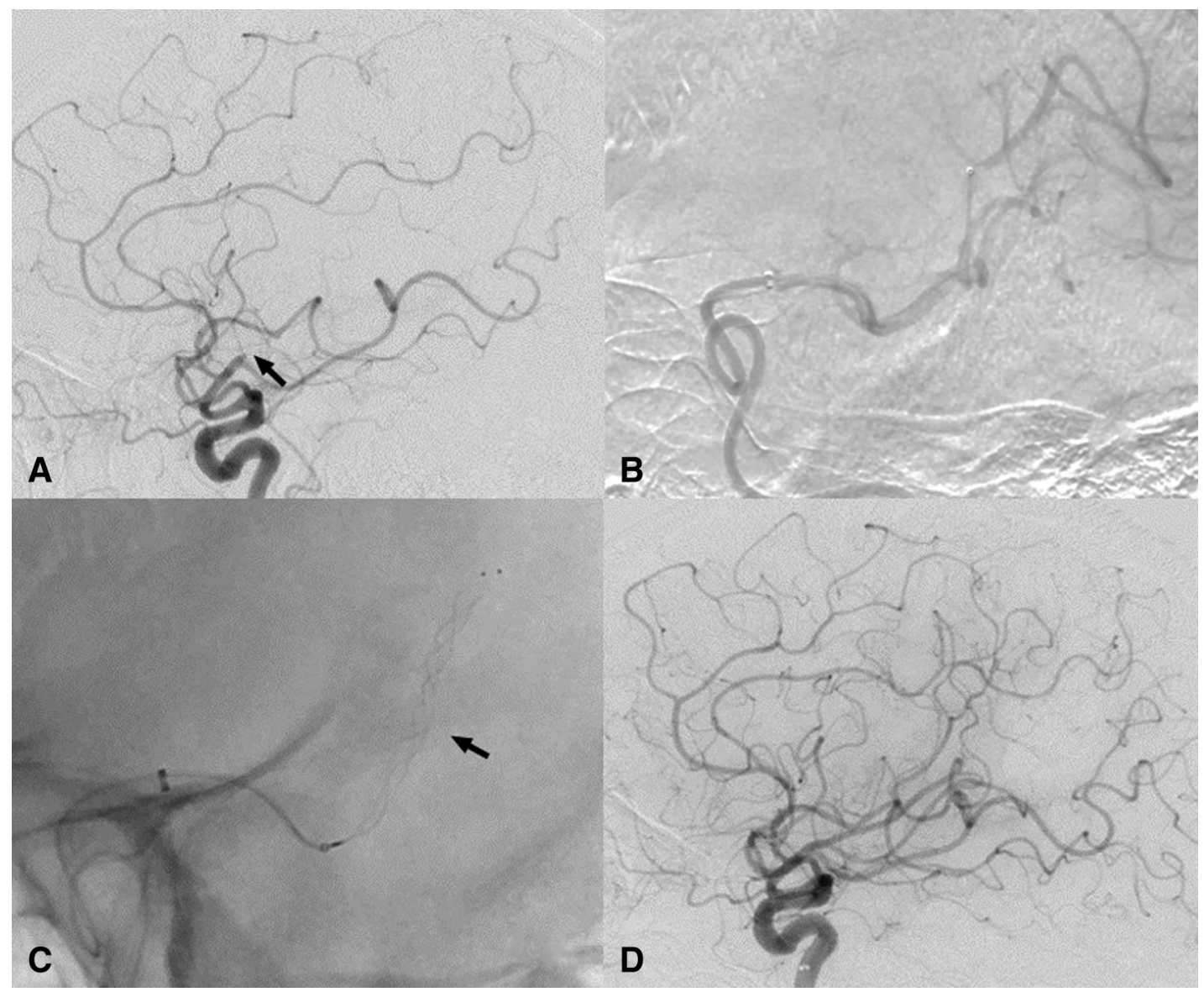

Fig. 2 (A) Right internal carotid artery angiography demonstrates occlusion of the right MCA M2 segment. (black arrow) (B) Dual injection angiography shows the occlusion site. (C) A Trevo $3 \times 20 \mathrm{~mm}$ was deployed in the right MCA M2 segment. The black arrow shows the site of occlusion. (D) Post-thrombectomy angiography shows recanalization of the right M2 segment following a single pass of the stent-retriever and aspiration with the ACE68 catheter. MCA: middle cerebral artery

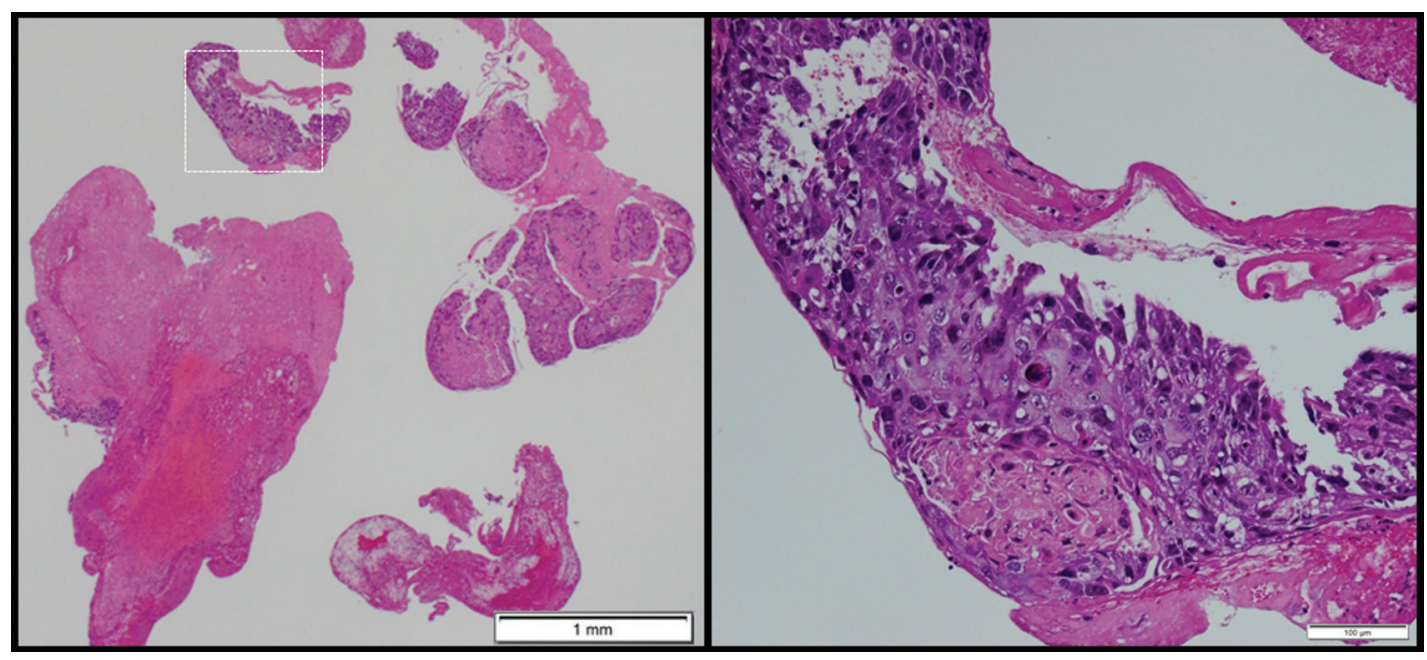

Fig. 3 Histopathology shows thrombus composed of fibrin and squamous cell carcinoma (hematoxylin-eosin staining) 


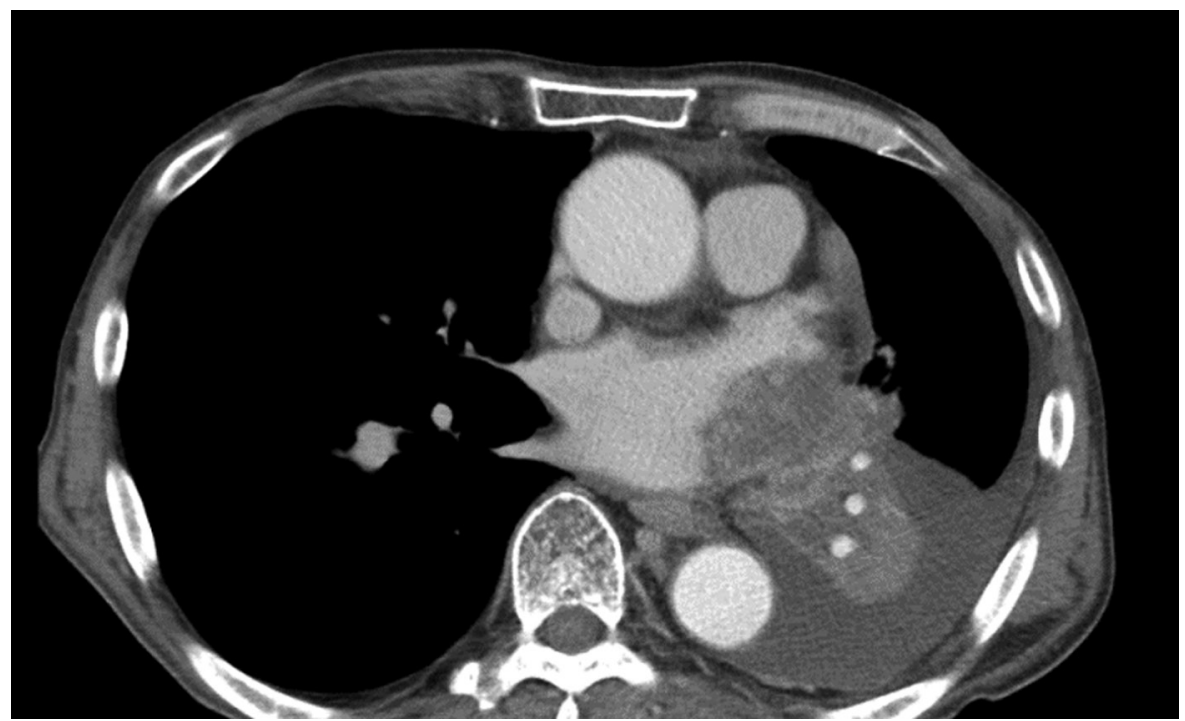

Fig. 4 Chest contrast CT shows lung cancer invading the pulmonary vein and left atrium. CT: computed tomography

condition was complicated by paroxysmal atrial fibrillation, dabigatran was administrated. The patient was transferred to the previous hospital for continuation of treatment for lung cancer 7 days after operation. The patient developed massive hemoptysis on the 36th postoperative day and died on the 40th postoperative day.

\section{Discussion}

We diagnosed a patient with tumor embolism by pathological examination of the thrombus retrieved by MT.

Due to the recent increase in patients with indications for MT, reports of detection of tumor cells by pathological examination of retrieved thrombi have been published. The 15 cases that have been reported are shown in Table $1 .^{1-14)}$

Cerebral embolism due to extracardiac tumor is considered to be caused by vascular infiltration of the tumor. In the present case, the tumor infiltrated the pulmonary vein and left atrium. Of the 15 reported cases of tumor embolism, 4 had extracardiac tumor. Of the four cases of extracardiac tumor, three had lung cancer infiltrating the pulmonary vein and left atrium, ${ }^{10,11,14)}$ and one had phyllodes tumor of the breast with pulmonary metastasis invading the pulmonary vein. ${ }^{1)}$

The thrombus retrieved from our patient pathologically consisted of $70 \%$ thrombotic components and 30\% tumor components. Ikeda et al. ${ }^{15)}$ treated patients with cerebral embolism due to myxoma of the heart by IV rt-PA therapy, and reported that the effectiveness of IV rt-PA was limited against emboli with a high tumor component percentage. IV rt-PA therapy was contraindicated in our patient because of hemoptysis, but considering the high percentage of thrombotic components, recanalization may have been achieved if IV rt-PA therapy had been performed.

Concerning MT for tumor embolism, Tsurusaki et al. ${ }^{14)}$ reported that the hardness of the embolus is an important factor for recanalization, and that the push and fluff method using a Trevo was effective for a hard embolus of pulmonary squamous cell carcinoma. We also used the Trevo to treat our patient, deploying it by unsheathing, and were able to retrieve the embolus by one pass using the combined technique. Recanalization was considered to have been achieved easily because of the high percentage of thrombotic components and relative softness of the embolus.

Obtaining information about components of the embolus by preoperative imaging is beneficial for the prediction of the effectiveness of IV rt-PA, and selection of the device and technique for thrombectomy. Brinjikji et al. ${ }^{16)}$ reported that the positive susceptibility vessel sign on T2*-weighted imaging and the positive hyper-dense artery sign on CT are indications of a high percentage of thrombotic components in the embolus. Our patient underwent imaging examinations at the previous hospital, but as T2*-weighted imaging and CT were not included, these signs were not evaluated.

The thrombi retrieved from the four patients with cerebral embolization due to extracardiac tumors shown in Table 1 were white and hard, and had different morphological characteristics from usual thormbi. ${ }^{1,10,11,14)}$ However, the appearance and elasticity of the embolus in our patient did not differ from those of usual thrombi. We initially considered the etiology of infarction to be cardiogenic cerebral embolism because of the history of paroxysmal atrial 
Table 1 Summary of reported cases of diagnosed as tumor embolism by thrombo-pathology

\begin{tabular}{|c|c|c|c|c|c|c|c|c|}
\hline Case & References & Age/Sex & IV rt-PA & Site of Occlusion & Technique of MT & Morphology of Colt & Pathology of Clot & Tumor \\
\hline 1 & Bhatia (2010) & $62 \mathrm{~F}$ & $(-)$ & ICA top & SR & $\begin{array}{l}\text { whitish and tissue-like } \\
\text { and not like a normal clot } \\
\text { in either appearance or } \\
\text { texture }\end{array}$ & phyllodes tumor of the breast & $\begin{array}{l}\text { phyllodes tumor } \\
\text { of the breast }\end{array}$ \\
\hline 2 & Tejada (2014) & $64 \mathrm{~F}$ & $(+)$ & MCA M1 & SR & $\begin{array}{l}\text { white granular surface of } \\
\text { soft consistency and } \\
\text { papilliform appearance }\end{array}$ & $\begin{array}{l}\text { branching papillary lesions } \\
\text { consistent with papillary } \\
\text { fibroelastoma }\end{array}$ & papillary fibroelastoma \\
\hline 3 & Baek (2014) & $46 \mathrm{M}$ & $(+)$ & ICA/MCA M2 & ADAPT/ADAPT & $\begin{array}{l}\text { large amout of a gray, } \\
\text { whitish-to-reddish }\end{array}$ & cardiac myxoma & cardiac myxoma \\
\hline 4 & Ptacek (2014) & $34 \mathrm{NR}$ & $(+)$ & MCA M1/M2 & SR & $\begin{array}{l}\text { gross appearance and } \\
\text { consistency }\end{array}$ & tumorous embolus of myxoma & myxoma \\
\hline 5 & Vega (2015) & $11 \mathrm{M}$ & $(-)$ & MCA M1/PcomA & CT/ADAPT & $\begin{array}{l}\text { gelatinous and friable } \\
\text { consistency }\end{array}$ & NR & cardiac myxoma \\
\hline 6 & Ryu (2015) & $34 \mathrm{M}$ & $(+)$ & MCA M1 & CT & $\begin{array}{l}\text { round, whitish, and } \\
\text { elastic hard }\end{array}$ & $\begin{array}{l}\text { tumorous tissue originating } \\
\text { from a cardiac tumor }\end{array}$ & cardiac myxoma \\
\hline 7 & Byon (2016) & $55 \mathrm{M}$ & $(+)$ & ICA & ADAPT & yellow in color & $\begin{array}{l}\text { high-grade } \\
\text { undifferentiated sarcoma }\end{array}$ & unclassified sarcoma \\
\hline 8 & Chung (2016) & $4 \mathrm{M}$ & $(+)$ & MCA M1 & SR & brown gelatinous material & cardiac myxoma & cardiac myxoma \\
\hline 9 & Biraschi (2016) & $75 \mathrm{M}$ & $(-)$ & MCA M1 & ADAPT & $\begin{array}{l}1 \mathrm{~cm} \text { white-pink hard } \\
\text { tissue-like material }\end{array}$ & papillary fibroelastoma & papillary fibroelastoma \\
\hline 10 & Zander (2016) & $58 \mathrm{M}$ & $(-)$ & MCA M2 & SR & small tissue fragment & $\begin{array}{l}\text { undifferentiated non-small cell } \\
\text { carcinoma of the lung }\end{array}$ & $\begin{array}{l}\text { pulmonary } \\
\text { adenocarcinoma }\end{array}$ \\
\hline 11 & Zander (2016) & $46 \mathrm{~F}$ & $(-)$ & MCA M1 & SR & NR & myxoma & cardiac myxoma \\
\hline 12 & Pop (2017) & $56 \mathrm{M}$ & $(-)$ & $\mathrm{BA} / \mathrm{ICA}$ & CT & $\begin{array}{l}\text { compact and purely } \\
\text { tumorous/Both tumorous } \\
\text { and thrombotic fragments }\end{array}$ & Sarcomatoid carcinoma & Pulmonary hilum tumor \\
\hline 13 & Salam (2018) & $25 \mathrm{M}$ & $(+)$ & MCA M1 & SR & pale,white soft & papillary fibroelastoma & papillary fibroelastoma \\
\hline 14 & Passhak (2018) & $49 \mathrm{M}$ & $(-)$ & MCA M1 & NR & NR & Liposarcoma & liposarcoma \\
\hline 15 & Tsurusaki (2019) & $72 \mathrm{M}$ & $(-)$ & ICA & SR & $\begin{array}{l}\text { elastic and hard compared } \\
\text { with that of intracardiac } \\
\text { thrombus }\end{array}$ & Squamous cell carcinoma & $\begin{array}{l}\text { Pulmonary squamous } \\
\text { cell carcinoma }\end{array}$ \\
\hline 16 & This case & $64 \mathrm{M}$ & $(-)$ & MCA M2 & CT & soft, red and thrombotic & Squamous cell carcinoma & $\begin{array}{l}\text { Pulmonary squamous } \\
\text { cell carcinoma }\end{array}$ \\
\hline
\end{tabular}

ICA: internal carotid artery; MCA: middle cerebral artery; PcomA: posterior communicating artery; BA: basilar artery; IV rt-PA: intravenous rt-PA; MT: mechanical thrombectomy; SR: stent-retriever; ADAPT: a direct aspiration first pass technique; CT: combined technique; NR: not reported 
fibrillation, but eventually diagnosed as tumor embolism based on pathological findings. It is important to proactively perform pathological examination of the retrieved thrombi because tumor cells may be detected even in apparently usual thrombi by pathological examination, leading to accurate subtyping of stroke. Pathological examination is considered particularly important for patients with a preoperatively unknown source of embolus, cancer patients, and patients with a history of cancer.

\section{Conclusion}

Tumor embolism due to extracardiac tumors is caused by vascular invasion of the tumor. Even when the characteristics of the retrieved embolus are similar to those of usual thrombus, pathological examination of the embolus may lead to accurate subtyping of stroke.

\section{Disclosure Statement}

The authors declare no conflicts of interest.

\section{References}

1) Bhatia $\mathrm{S}, \mathrm{Ku} \mathrm{A}, \mathrm{Pu} \mathrm{C}$, et al: Endovascular mechanical retrieval of a terminal internal carotid artery breast tumor embolus. J Neurosurg 2010; 112: 572-574.

2) Tejada J, Galiana A, Balboa O, et al: Mechanical endovascular procedure for the treatment of acute ischemic stroke caused by total detachment of a papillary fibroelastoma. $J$ Neurointerv Surg 2014; 6: e37.

3) Baek SH, Park S, Lee NJ, et al: Effective mechanical thrombectomy in a patient with hyperacute ischemic stroke associated with cardiac myxoma. J Stroke Cerebrovasc Dis 2014; 23: e417-419.

4) Garcia-Ptacek S, Matias-Guiu JA, Valencia-Sánchez C, et al: Mechanical endovascular treatment of acute stroke due to cardiac myxoma. J Neurointerv Surg 2014; 6: e1.

5) Vega RA, Chan JL, Anene-Maidoh TI, et al: Mechanical thrombectomy for pediatric stroke arising from an atrial myxoma: case report. J Neurosurg Pediatr 2015; 15: 301-305.

6) Ryu B, Ishikawa $T$, Sato $S$, et al: Mechanical endovascular recanalization in a patient with middle cerebral artery occlusion by tumorous emboli originating from cardiac myxoma. NMC Case Rep J 2015; 2: 53-56.

7) Byon JH, Kwak HS, Chung GH, et al: Acute stroke from tumor embolus in a patient with cardiac sarcoma: aspiration thrombectomy with penumbra catheter. Interv Neuroradiol 2016; 22: 88-90.

8) Chung YS, Lee WJ, Hong J, et al: Mechanical thrombectomy in cardiac myxoma stroke: a case report and review of the literature. Acta Neurochir (Wien) 2016; 158: 1083-1088.

9) Biraschi F, Diana F, Alesini F, et al: Effective ADAPT thrombectomy in a patient with acute stroke due to cardiac papillary elastofibroma: histological thrombus confirmation. J Stroke Cerebrovasc Dis 2016; 25: e185-187.

10) Zander T, Maynar J, López-Zárraga $F$, et al: Mechanical thrombectomy in patients with tumour-related ischaemic stroke. Interv Neuroradiol 2016; 22: 705-708.

11) Pop R, Mihoc D, Manisor M, et al: Mechanical thrombectomy for repeated cerebral tumor embolism from a thoracic sarcomatoid carcinoma. J Neurointerv Surg 2018; 10: e26.

12) Salam KA, Rafeeque M, Hashim H, et al: Histology of thrombectomy specimen reveals cardiac tumor embolus in cryptogenic young stroke. J Stroke Cerebrovasc Dis 2018; 27: e70-e72.

13) Passhak M, Amsalem Y, Vlodavsky E, et al: Cerebral liposarcoma embolus from heart metastasis successfully treated by endovascular extraction followed by cardiac surgery. Vasc Endovascular Surg 2018; 52: 653-657.

14) Tsurusaki Y, Takahara K, Koga N, et al: A case of mechanical reperfusion therapy for cerebral infarction induced by tumor embolism from lung cancer. JNET J Neuroendovasc Ther 2019; 13: 342-347.

15) Ikeda $T$, Oomura $M$, Sato $C$, et al: Cerebral infarction due to cardiac myxoma developed with the loss of consciousness immediately after defecation-a case report. Rinsho Shinkeigaku 2016; 56: 328-333. (in Japanese)

16) Brinjikji W, Duffy S, Burrows A, et al: Correlation of imaging and histopathology of thrombi in acute ischemic stroke with etiology and outcome: a systematic review. J Neurointerv Surg 2017; 9: 529-534. 